\title{
Experiência formativa no Curso para Gestores de Instituições Conveniadas/Cepis em Brasília
}

\section{Training experience in the Course for Managers of Agreed Institutions/Cepis in Brasilia}

Bianca Regina de Lima Salomão, Helane Araújo de Lima Moreira, Angélica Inês Miotto Secretaria de Educação do DF

\begin{abstract}
Resumo
$\mathrm{O}$ artigo apresenta resultados de pesquisa sobre o curso "Gestão Escolar: competências essenciais da Equipe Gestora das Instituições Conveniadas e dos CEPIs" da Secretaria de Estado de Educação do Distrito Federal (SEDF) que foi ofertado em 2016. A investigação está centrada na abordagem qualitativa e utiliza como técnica de coleta de dados a pesquisa bibliográfica, pesquisa de campo e a análise de documentos. Foi possível pontuar resultados em duas perspectivas emergentes dos participantes do curso, a saber: (i) as práticas compartilhadas das experiências educativas; (ii) a aproximação dos discursos com as diretrizes e os pressupostos do currículo da SEDF.

Palavras-chave: formação docente, currículo, organização social
\end{abstract}

\begin{abstract}
The paper presents research results about the course "School Management: essential competences of the Management Team of Agreed Institutions and CEPIs" of the Secretaria de Estado de Educação do Distrito Federal (SEDF), which was offered in 2016. The research is centered on the qualitative approach and uses as a data collection technique bibliographic research, field research and document analysis. It was possible to score results in two emerging perspectives of the course participants, namely: (i) the shared practices of educational experiences; (ii) the approximation of discourses with the guidelines and assumptions of the SEDF curriculum.

Keywords: teacher training, curriculum, social organization
\end{abstract}

\section{Introdução}

O artigo 205 da Constituição Brasileira determina que a educação é direito de todos e dever do Estado. Já o artigo 208 estabelece que a educação será efetivada mediante a garantia de oferta, pelo Estado, de diferentes níveis e etapas educacionais, dentre as quais está a Educação Infantil, ofertada em creches e pré-escolas para as crianças de zero a cinco anos de idade.

A Educação Infantil é a primeira etapa da educação básica e de acordo com a Lei ${ }^{\circ} 9.394 / 96$, art. 29, tem como finalidade o desenvolvimento integral da criança de zero a cinco anos de idade em seus aspectos físico, afetivo, intelectual, linguístico e social, complementando a ação da família e da comunidade.

$\mathrm{O}$ atual Plano Nacional de Educação (PNE) determina diretrizes, metas e estratégias para a política educacional. $O$ referido PNE, que tem vigência de dez anos (2014/2024), estabelece como Meta 1 a universalização, até 2016, da Educação Infantil na pré-escola para as crianças de 4 a 5 anos de idade e a ampliação da oferta do atendimento em creches, de forma a atender, no mínimo, $50 \%$ das crianças de até 3 anos até o final da vigência desse Plano (BRASIL, 2015).

Nesse momento é preciso retomarmos o processo histórico para compreendermos como a oferta da Educação Infantil esteve atrelada a uma função predominantemente assistencialista e com vínculo direto com o Governo Federal. Em um trecho do documento da Política Nacional de Educação Infantil podemos constatar tal fato:

A educação de crianças de 4 a 6 anos insere-se nas ações do Ministério da Educação (MEC) desde 1975, quando foi criada a Coordenação de Educação Pré-Escolar. $\mathrm{Na}$ área da Assistência Social do Governo Federal outro órgão também se incumbia do atendimento "pré-escolar" por meio de programa específico de convênio direto com instituições comunitárias, filantrópicas e confessionais que atendiam crianças de 0 a 6 anos das camadas mais pobres da população. O Programa, que previa o auxílio financeiro e algum apoio técnico, foi desenvolvido pela Legião Brasileira de Assistência do então Ministério da Previdência e Assistência Social, desde 1977. (BRASIL, Política Nacional de Educação Infantil: pelos direitos das crianças de zero a seis anos, 2006, p.7)

Em 2011, o Governo de Brasília, por meio da SEDF, aderiu ao Programa Nacional de Reestruturação e Aquisição de Equipamentos para a Rede Escolar Pública de Educação Infantil (Proinfância) do Ministério da Educação. Os Centros de Educação da Primeira Infância (CEPIs), frutos dessa parceria entre SEDF e o MEC, são administrados por meio de conveniamentos com instituições privadas sem fins lucrativos, devidamente acompanhados pelo poder público distrital. 
Desse modo, é preciso ter presente que as Organizações Sociais (OSs) caracterizam-se por um novo modelo de gestão pública, ou seja, são executoras de prestação de serviços. Portanto, entendeu-se que as OSs configuram-se como um recente modelo político e de orientação filosófica da gestão pública no qual o Estado é apenas o responsável pelo gerenciamento e controle das políticas públicas.

Dentre as normas que abordam critérios e exigências que balizam o funcionamento das instituições de Educação Infantil encontra-se a formação de profissionais. Nesse sentido, atendendo a demanda da SEDF, o curso, objeto de estudo deste artigo, foi criado para formar a equipe gestora de Instituições Conveniadas e dos Centros de Educação da Primeira Infância (CEPI's). Sendo assim, a função do curso, foi oportunizar a formação de profissionais terceirizados que trabalham para atender a demanda da rede pública.

Atualmente a rede pública de ensino do Distrito Federal conta com aproximadamente 667 escolas. Entre essas, 590 são urbanas e 77 rurais. A SEDF atende em toda a educação básica - Ensino Infantil (creche e pré-escola), Ensino Fundamental, Ensino Médio, Educação de Jovens e Adultos (EJA) e Educação Especial - aproximadamente 463,5 mil estudantes, nas cerca de 17 mil turmas, contando com o respaldo pedagógico de aproximadamente 27,6 mil professores ativos e 5,5 mil contratos (SEDF, 2017).

\section{Metodologia}

A natureza do objeto da pesquisa foi baseada em uma abordagem qualitativa em que o ambiente foi fonte direta dos dados. Como técnica de coleta de dados foram utilizados: pesquisa bibliográfica, questionário com perguntas abertas e fechadas (avaliação final do curso), registros do Ambiente Virtual de Aprendizagem (AVA) Moodle e análise de documentos.

De acordo com Stake (2010, p. 34), o pensamento qualitativo tem uma ampla coleção de formas: "Ele é interpretativo, baseado na experiência, situacional e humanístico." Nesse sentido, o nosso objetivo centrou-se em busca de evidências que nos posibilitassem compreender o alcance do potencial formativo desse curso relacionado a construção de novos saberes.

As várias fontes de dados na indagação qualitativa possibilitaram capturar o sentido do fenômeno em estudo. É importante ressaltar que a perspectiva metodológica assumida no Curso "Gestão Escolar: competências essenciais da Equipe Gestora das Instituições Conveniadas e dos CEPIs" considerou as teorias da aprendizagem e do desenvolvimento humano que resguardam a heterogeneidade de tempos, espaços e modos de aprender dos indivíduos, reconhecendo que o conhecimento é construído a partir da interlocução sociocultural e intrapessoal (Vygotsky, 2001).

Ressalta-se que as ferramentas utilizadas permitiram compreender o fenômeno de maneira dinâmica, ajudando a encontrar particularidades e similaridades, que vai ao encontro da afirmação de Stake: "algumas vezes nossas histórias serão breves, um momento no tempo, contribuindo pouco para o conhecimento experiencial, mas dando vida a um problema central para a pesquisa ou a um que mostre a complexidade" (2010, p.188).

\section{Contextualizando a formação}

O curso em questão foi ofertado entre abril e dezembro de 2016 com carga horária de 180 horas divididas em: 144 horas indiretas (trabalhos práticos e a plataforma Moodle) e 36 horas diretas, totalizando 12 encontros presenciais divididos em três polos: Plano Piloto, Taguatinga e Sobradinho. O objetivo principal foi formar a equipe gestora de Instituições Conveniadas e dos CEPI's para a compreensão das políticas públicas da Educação Infantil e dos fundamentos teórico-metodológicos que embasam a organização do trabalho escolar na SEDF na perspectiva do direito da criança à educação.

Em relação ao número de cursistas, contamos com 134 inscrições de diretores, vice-diretores, coordenadores pedagógicos, secretários escolares e executores pedagógicos e financeiros das Coordenações Regionais de Ensinos que atendem as escolas de Brasília. Deste total, 86 finalizaram o curso.

Seis professoras formadoras do Centro de Aperfeiçoamento dos Profissionais da Educação (EAPE) foram as responsáveis por atenderem as nove turmas formadas. Destaca-se que a EAPE é setor integrante da SEDF e tem como responsabilidade a formação continuada de todos os profissionais da educação.

Dentre suas funções, no decorrer do curso, destacam-se: a organização dos módulos (conteúdos); docência; atendimento aos alunos em horários extra-classe; coordenação coletiva para aprofundamento/validação dos conteúdos e planejamento e avaliação dos encontros presenciais.

A ementa buscou aproximar-se de questões relativas as práticas de gestão no espaço escolar. Tratou sobre as seguintes questões: políticas públicas para a Educação Infantil; direito da criança à educação; dimensões: administrativa e de pessoas na gestão escolar; Projeto Político Pedagógico como organização do trabalho escolar; pressupostos teóricos do Currículo em Movimento da SEDF; organização curricular e prática pedagógica; avaliação na Educação Infantil.

Como metodologia pedagógica foram privilegiadas as situações didáticas em que os saberes e experiências dos cursistas viessem à tona por meio de sua problematização, fundamental para evidenciar sua prática social, evidências do que sabem sobre o assunto, o que pensam a respeito, quais suas descobertas, quais caminhos percorreram para encontrar as respostas. Foram propostas atividades que instrumentalizassem os cursistas, possibilitando a reflexão crítica e criativa.

$\mathrm{O}$ acompanhamento das aprendizagens foi realizado pelas professoras formadoras. Esse processo foi fundamental para o (re)planejamento do trabalho pedagógico do curso que pautou-se nos sentidos atribuídos pelos cursistas sobre aquilo que estudaram, na articulação entre o conhecimento de mundo e dos 
conteúdos científicos, a prática social inicial e as sínteses elaboradas durante o processo de estudo.

\section{Análise dos dados}

Foi observado que o curso apresentou uma porcentagem positiva de cursistas habilitados: $64,18 \%$. O cálculo levou em conta o total de matrículas efetivadas (134 matrículas). É necessário ressaltar que deste total: $17,10 \%$ dos cursistas nunca compareceram a nenhum encontro; $9,7 \%$ desistiram ao longo do curso e $8,9 \%$ não foram habilitados.

$\mathrm{O}$ número elevado de cursistas que "nunca compareceram" preocupou a equipe de professoras formadoras. Nesse sentido a equipe optou por "resgatar" esses cursistas durante o $1^{\circ}$ bimestre, porém esta ação não se mostrou efetiva. A hipótese levantada para a ocorrência dessa situação foi a de que muitos desistentes se inscreveram para frequentarem outro curso, voltado para a formação exclusiva de gestores efetivos recém eleitos da rede pública da SEDF. Foi constatada que a similaridade entre os nomes dos dois cursos causou confusão no momento da efetivação das matrículas. Sendo assim, é preciso que esta situação seja considerada e evitada em futuras ofertas sendo sugerido mais atenção em relação a nomenclatura dos cursos e mais objetividade nos informativos disponibilizados para os cursistas no momento das inscrições.

Em relação as questões pedagógicas foi possível pontuar resultados positivos no processo de aprendizagem em duas perspectivas, a saber: (i) as práticas compartilhadas das experiências educativas; (ii) a aproximação dos discursos com as diretrizes e os pressupostos do currículo da SEDF.

Antes de discutirmos estes dados, é preciso ressaltar que em muitos momentos do curso emergiram também como pontos de discussão, as relações entre o poder público e o privado.

Di Pietro (2009) afirma que a privatização deve ser: "[...] entendida em sentido amplo, de modo a abranger a todos os institutos que o Estado vem lançando mão para diminuir o seu aparelhamento administrativo, o seu quadro de pessoal, o regime jurídico administrativo a que se sujeita."

Nos debates com os cursistas ficaram evidentes questões que podem estar interferindo na qualidade da educação como: demora para o repasse de verbas e oferta de baixos salários para os professores e monitores o que muitas vezes acarreta alto índice de rotatividade dos funcionários. Tendo estes problemas em vista, recorremos a Pino (2002) quando afirma que:

A formação profissional tem sido vista como uma resposta estratégica, mas polêmica, aos problemas postos pela globalização da economia, pela busca da qualidade e da competitividade, pelas transformações no mundo do trabalho e pelo desemprego estrutural. Vários estudos afirmam que a inserção e o ajuste dos países dependentes ao processo de globalização e de reestruturação produtiva, sob uma nova base científica e tecnológica, dependem da educação básica, de formação profissional, qualificação e requalificação (2002, p.76).
Como já relatado anteriormente nas reflexões e diálogo realizados entre professores formadores e cursistas ficou evidente a percepção dos mesmos em relação a estas questões. A seguir, destacamos o relato de um cursista:

A realização do curso ampliou o meu conhecimento, sendo importante destacar a importância das experiências junto as demais instituições. As dinâmicas, os textos os fóruns de participação, possibilitaram aos participantes uma avaliação continua das práticas relacionadas a gestão escolar. Outro momento importante foi a permissão da nossa professora para colocações inerentes ao nosso peculiar trabalho, historicidade, lutas, conquistas e ações que vão além do simples conteúdo, sendo possível constatar que a politica de educação veio ao nosso encontro posteriormente, pois as instituições já realizavam com relevância este trabalho de social educação, tendo uma visão transformadora mediante a uma sociedade que grita por justiça social. Esperamos continuar este curso com outros temas relacionados as práticas burocráticas do Estado, assim em momentos de crise, pensa-se mais na proteção do capital, esquecendo o investimento prioritário no ser humano e suas diversas potencialidades. Basta observar a estrutura política de 1970 e as escolas de 2016, mudou-se o pensamento, porém as práticas são as mesmas. Educação Infantil não é investimento é o reconhecimento amplo da dignidade humana para construção de uma verdadeira nação.

Segundo Gohn (2011) o novo perfil das Organizações Sociais desenha um tipo de entidade mais voltada para a prestação de serviços e alerta sobre a tendência de alguns administradores públicos conduzirem as políticas sociais para o campo compensatório, da filantropia e da caridade remetendo as ações ao campo do burocratismo e até mesmo do velho clientelismo.

\section{As práticas compartilhadas das experiências educativas}

Um dos princípios da qualidade social na educação está relacionado à formação de profissionais. Percebe-se que a inserção da Educação Infantil na primeira etapa da educação básica acelera a necessidade da formação educacional dos educadores da primeira infância. Até a publicação da Lei de Diretrizes e Bases da Educação Nacional de 1996 a formação profissional do professor não era exigência legal para o exercício da função de crianças pequenas, especialmente das crianças de zero a três anos.

Nessa sequência, é mister, que no contexto de formação continuada dos profissionais da educação, as equipes que atuam em escolas exerçam papel fundamental na realização e proposição de práticas formadoras. De acordo com Imbernón (2010), estas são questões fundamentais na construção da identidade docente:

Não podemos separar a formação do contexto de trabalho porque nos enganaríamos em nosso discurso. Ou seja, tudo o que se explica não serve para todos nem se aplica a todos os lugares. O contexto condicionará as práticas formadoras, bem 
como sua repercussão nos professores, e sem dúvida, na inovação e na mudança. (Imbernón, 2010, p.9)

O curso em questão focou a atenção exclusivamente na equipe gestora das unidades escolares atendidas nesta primeira oferta. Segundo Santos $(2008$, p.40) "a gestão relaciona-se com a atividade de impulsionar uma organização, o que cria grandes identidades entre teorias de gestão e teorias de inovação". No trabalho desenvolvido, visamos debater com o grupo a importância das equipes gestoras estarem à frente de todas as questões que permeiam o ambiente escolar, principalmente as relacionadas aos aspectos pedagógicos, que incluem a sociedade, os alunos e a comunidade escolar.

Nessa direção, destacamos relatos de cursistas:

$\mathrm{O}$ curso contribuiu bastante, possibilitando um repensar das minhas práticas pedagógicas. A troca com outras realidades, novas formas de administração de conflitos e as leituras e discussões de importantes documentos que norteiam nossa prática, ampliou meus conhecimentos e certamente, facilitará meus futuros planejamentos (Avaliação final do curso).

O curso contribuiu muito para minha prática diária no meu ambiente de trabalho, pois antes de fazer este curso, o meu conhecimento era somente na parte financeira. Agora ampliei meu leque de conhecimento na área pedagógica (Avaliação final do curso).

A metodologia pedagógica utilizada ao longo do curso incentivou situações didáticas em que os saberes e experiências dos cursistas viessem à tona por meio de sua problematização com o intuito de evidenciar suas práticas. Essa opção didática, que privilegiou além da reflexão, o compartilhamento e a relação teoria/prática, foi pontuada várias vezes pelos cursistas na avaliação final do curso. A seguir apresentamos alguns depoimentos:

Durante o curso foi possível compartilhar opiniões, posicionamentos e ações em diversos planos. Dessa forma conseguimos analisar melhor nossos procedimentos e adequar melhor nossa forma de agir, através de vivências apresentadas pelos relatos dos colegas. (Avaliação final do curso)

A interação com outras pessoas que trabalham na área e em diversas funções proporcionou uma troca de experiências valiosa. Muitas pessoas tiveram a oportunidade de conhecer o trabalho que é realizado nos CEPIs e nas Conveniadas, assim valorizando e respeitando ainda mais o nosso trabalho [...] (Avaliação final do curso)

Com certeza este curso veio somar o que as instituições vivenciam no dia a dia, este contato com outros colegas de instituições foi muito gratificante, mostra uma mesma linguagem de vivências, dificuldades, questionamentos entre si. Este curso nos trouxe um conhecimento amplo e rico, que compartilhei e compartilho na minha instituição em atividades com monitores e professores. Parabenizo a EAPE e toda a equipe por este curso e principalmente por ter lembrado da instituições. (Avaliação final do curso)

Segundo Valadares a interação dialógica entre indivíduos e o intercâmbio de ideias promove o desenvolvimento cognitivo do sujeito, pois os conhecimentos são socialmente definidos e o sujeito depende da interação social para construção e validação dos conceitos (Valadares, apud Valaski, 2003, p. 23). A afirmação do referido autor foi ao encontro do que foi vivenciado junto ao grupo de cursistas das nove turmas.

Finalizamos destacando Marchesi (2004) quando afirma que só a partir das condições reais de cada escola, é possível melhorar a organização interna e contribuir para criar uma cultura mais favorável à mudança educacional.

\section{A aproximação dos discursos com as diretrizes e os pressupostos do currículo da SEDF}

Esta categoria de análise, que considera a aproximação dos discursos com as diretrizes e os pressupostos do currículo da SEDF, configurou-se como um dos principais objetivos do curso, que foi exatamente o de promover acesso e discussão sobre temáticas relativas a políticas públicas para a Educação Infantil, Projeto Político Pedagógico, pressupostos teóricos e organização do currículo, prática pedagógica e avaliação na Educação Infantil.

Embora as Conveniadas e CEPIs tenham autonomia garantida, estas não podem desconsiderar as orientações, diretrizes e legislações emanadas do sistema público. Sendo assim, o curso se preocupou em situar a escola, sua organização e funcionamento no contexto da administração pública. A equipe gestora precisa atuar com base em um conjunto de normas e procedimentos ao qual está vinculada. Para isso, compreender a organização do sistema de administração pública da educação é fundamental.

Com satisfação, foi observado pela equipe de professoras formadoras, que esta categoria, emergiu também nos depoimentos de vários cursistas na avaliação final do curso. Foi possível observar pelos relatos que as temáticas relacionadas a esta categoria foram levantadas nas avaliações. Destacamos a seguir alguns trechos:

Sim, o curso contribuiu bastante, possibilitando um repensar das minhas práticas pedagógicas. A troca de experiências o contato com outras realidades, novas formas de administração e conflitos e as leituras e discussões de importantes documentos que norteiam nossa prática, ampliou meus conhecimentos e certamente, facilitará meus futuros planejamentos. (Avaliação final do curso)

Acredito que todo conhecimento alimenta a prática pedagógica, e no caso do curso voltado para as CRECHES, foi extremamente gratificante saber que a SEDF também se preocupa com a nossa prática. (Avaliação final do curso)

O curso sim foi de grande valia pois podemos estar em contato com outras realidades achei muito importante a secretaria pensar na equipe gestora das conveniadas e buscando conhecer nossas 
necessidades e aflições para desenvolver um trabalho com qualidade trazendo assuntos mais atuais dentro da nossa realidade nos oferecendo propostas didáticas criativas e envolventes tornando o conteúdo atrativo. (Avaliação final do curso)

Precisamos considerar que os serviços terceirizados no âmbito da educação pública do Distrito Federal, não estão mais somente relacionados aos serviços como conservação e limpeza mas agora envolvem também as áreas de gestão e docência. É preciso que as instituições que prestam serviço no âmbito da Educação Infantil se adequem as diretrizes que norteiam as ações no sistema público de ensino. Nesta análise, constatamos que esta formação configurou-se como uma estratégia importante nesse sentido.

Além disso, é preciso salientar que é tarefa do poder público assumir a formação dos referidos profissionais no sentido de refletir, orientar e garantir que os pressupostos e diretrizes sejam articulados conforme referências dos documentos norteadores da legislação voltada para o ensino público.

\section{Considerações finais}

Verificamos que a oferta e a garantia na proposição de programas de formação para profissionais em exercício na rede pública, particularmente nas Instituições Conveniadas, são aspectos importantes a serem considerados na construção de políticas públicas educativas. O investimento em formação precisa refletir na garantia da qualidade social e na escolarização das crianças atendidas na Educação Infantil.

Compreendemos ainda que, como docentes atuantes no âmbito do Centro de Aperfeiçoamento dos Profissionais da Educação (EAPE), e ainda, como professoras pesquisadoras dos cotidianos da formação continuada, as experiências vivenciadas no âmbito dos espaços formativos precisam extrapolar as esferas. Para compreender as interpretações que perpassam os cotidianos escolares é preciso dar voz e utilizar formas educativas potencializadoras que promovam a reflexão e o dialógo entre as várias instâncias do sistema educacional.

Por fim, as conclusões provisórias desta investigação caminham na direção de buscar outros olhares, novas formas, para objetivos a serem considerados em subsequentes desenhos de matrizes de programas de formação continuada.

\section{Referências}

Brasil. Constituição (1988). Constituição da República Federativa do Brasil promulgada em 5 de outubro de 1988. Brasília. Senado Federal, 1998.

Brasil. Lei 13.005, de 25 de junho de 2014. Aprova o Plano Nacional de Educação - PNE e dá outras providências. Disponível em: $<$ http://www.planalto.gov.br/ccivil_03/_ato2011-2014 /2014/lei/113005.htm>. Acesso em: 01/05/2017.

Brasil. Ministério da Educação. Secretaria de Educação Básica. Política Nacional de Educação Infantil: pelo direito das crianças de zero a seis anos à educação. Brasília: MEC/SEB, 2006. 32 p.

Di Pietro, M. S. Reflexões sobre as parcerias público-privadas. 2009. Disponível em: $<$ http:www.azevedosette.com.br/ppp/artigos/exibir/ref lexões_sobre_as_parcerias_publico-privadas/6>.

Acesso em: $16 / 03 / 2016$.

Gohn, M. G. Movimento Sociais na Contemporaneidade. Revista Brasileira de Educação, Minas Gerais, v.16, $\mathrm{n}^{\mathrm{o}}$ 47, pp. 333-351, maio/ago. 2011. Disponível em: $<$ www.scielo.br/pdf/rbedu/v16n47/v16n47a05.pdf $>$.

Acesso em: 17/03/2017.

Imbernón, F. Formação continuada de professores. Porto Alegre: Artmed, 2010. 120 p.

Marchesi, A. A prática das escolas inclusivas. In: Coll, César; Palacios, Jesus; Marchesi, Álvaro (Orgs.). Desenvolvimento psicológico e educação: necessidades educativas especiais e aprendizagem escolar. Porto Alegre: Artes Médicas, v. 3, 2. ed. 2004.

Pino, M. Del. Política Educacional, emprego e exclusão social. In: Gentili, P.; Frigotto, G. (Orgs). A cidadania negada: políticas de exclusão na educação e no trabalho, pp. 65-88. 3 ed. São Paulo: Cortez, 2002.

Santos, C. R. A gestão educacional e escolar para a modernidade. São Paulo: Cengage Lerning, 2008.

Secretaria de Estado de Educação. Unidades Escolares. Disponível

em:

$<$ www.se.df.gov.br/informacoes-da-rede/unidades-esc olares.html>. Acesso em: 17/03/2017.

Stake, Robert. Pesquisa Qualitativa. São Paulo: Penso, 2010.

Valaski, S. A aprendizagem colaborativa com o uso de computadores: uma proposta para a prática pedagógica. Curitiba, 2003. 107 f. Dissertação (Mestrado em Educação) - Programa de Pós-Graduação em Educação, Pontifícia Universidade Católica do Paraná.

Vygotsky, L. S. A construção do pensamento e da linguagem. São Paulo: Martins Fontes, 2001.

\section{Agradecimento}

Com menção de agradecimento a Fundação de Apoio à Pesquisa do Distrito Federal (FAPDF). 